\title{
The HIV-1 Rev trans-activator shuttles between the nucleus and the cytoplasm
}

\author{
Barbara E. Meyer ${ }^{1}$ and Michael H. Malim ${ }^{1-3}$ \\ ${ }^{1}$ Howard Hughes Medical Institute and ${ }^{2}$ Departments of Microbiology and Medicine, University of Pennsylvania School \\ of Medicine, Philadelphia, Pennsylvania 19104-6148 USA
}

The HIV-1 Rev protein is a nuclear trans-activator essential for the transport of unspliced viral transcripts to the cytoplasm. In this paper we demonstrate that Rev, rather than being confined to the nucleus, is constantly shuttling between the nucleus and the cytoplasm. We also show that inactivation of Rev's leucine-rich activation domain generates mutant proteins that not only fail to induce the nuclear export of viral transcripts but are also unable to enter the cytoplasm. On the basis of this correlation, we propose that Rev activates viral mRNA transport by directly binding to these RNAs and translocating, with them, to the cytoplasm. In addition, these results also identify, for the first time, a peptide sequence that is important for nuclear export.

[Key Words: HIV; Rev; nucleocytoplasmic transport]

Received February 22, 1994; revised version accepted May 19, 1994.

The transport of macromolecules across the eukaryotic nuclear membrane occurs through elaborate channeled structures known as the nuclear pore complexes (Feldherr et al. 1984; Dworetzky and Feldherr 1988; Hinshaw et al. 1992; for review, see Nigg et al. 1991; Davis 1992; Dingwall and Laskey 1992; Forbes 1992). Although the majority of macromolecules (namely proteins, RNAs, and complexes thereof) that traverse the nuclear membrane do so in a single direction, there are two broad classes of macromolecule that undergo bidirectional transport. On the one hand, there are RNAs and proteins that most likely cross the nuclear membrane only once in each direction, for example, the U1, U2, U4, and U5 small nuclear RNAs (snRNAs) (for review, see Goldfarb and Michaud 1991; Izaurralde and Mattaj 1992) and many of the ribosomal proteins (for review, see Warner 1989|, whereas on the other hand, there are proteins that are thought to constitutively cycle, or shuttle, between the nucleus and the cytoplasm (for review, see Goldfarb 1991; Laskey and Dingwall 1993). To date, shuttling activity has only been demonstrated for a limited number of proteins, for example, the nucleolar proteins nucleolin, B23/No38, and Nopp140 (Borer et al. 1989; Meier and Blobel 1992), certain heat shock-related proteins (Mandell and Feldherr 1990), the progesterone and glucocorticoid receptors (Guiochon-Mantel et al. 1991; Madan and DeFranco 1993), the heterogeneous nuclear ribonucleoprotein particle (hnRNP) Al protein (PiñolRoma and Dreyfuss 1992), and the U1 small nuclear ribonucleoprotein (snRNP) particle UlA protein (Kambach and Mattaj 1992). Nevertheless, proteins that shuttle are of considerable interest as they represent

${ }^{3}$ Corresponding author. excellent candidates not only for coupling nuclear and cytoplasmic processes to each other but also as cofactors important for the nucleocytoplasmic trafficking of other macromolecules.

The shuttling cycle can be segregated into two distinct stages, nuclear import and nuclear export. With respect to import, the sequences necessary for the nuclear uptake of many shuttling and nonshuttling proteins have been identified. In the majority of cases, these sequences, termed nuclear localization sequences (NLSs), have been shown to comprise either one or two short stretches of basic amino acid residues (for review, see Dingwall and Laskey 1991; Garcia-Bustos et al. 1991). NLS-dependent import is thought to be initiated by an interaction with cytoplasmic receptor proteins (Adam and Gerace 1991), a cascade of events then ensues that culminates in the translocation of the NLS-containing protein through the nuclear pore by a process requiring energy (for review, see Davis 1992; Dingwall and Laskey 1992; Forbes 1992; Gerace 1992). In sharp contrast to import, relatively little is known regarding either the mechanism or the determinants of protein export. Several studies using microinjection into the nucleus as the experimental approach have indicated that export to the cytoplasm is a specific (signal-mediated) process (Dingwall et al. 1982, 1988; Dworetzky and Feldherr 1988; Mandell and Feldherr 1990; Guiochon-Mantel et al. 1991). Until now, however, no positively acting peptide sequence that confers protein nuclear export has been defined. In a recent study of the shuttling of nucleolin, a rather different conclusion was reached, namely, that the capacity for nuclear export can be determined not by a specific sequence but, rather, by a protein's incomplete retention by the nucleus (Schmidt-Zachmann et al. 1993). 
When considering the potential for modulated nucleocytoplasmic transport of macromolecules, it is of interest to review the role of the virally encoded Rev transactivator in the regulation of human immunodeficiency virus type 1 (HIV-1) mRNA expression (for review, see Pavlakis and Felber 1990; Cullen 1991). In virally infected cells, the full-length $\sim 9-\mathrm{kb}$ viral transcript is spliced inefficiently to yield an array of transcripts that includes the 9-kb mRNA itself, singly spliced $\sim 4-\mathrm{kb}$ mRNAs, and fully spliced $\sim 2-\mathrm{kb}$ mRNAs (Muesing et al. 1985; Kim et al. 1989; Felber et al. 1990; Robert-Guroff et al. 1990; Schwartz et al. 1990|. Because the 9- and 4-kb mRNAs have retained introns as well as functional splice sites, their export from the nucleus, rather than being constitutive, is absolutely dependent on the Rev protein (Chang and Sharp 1989; Emerman et al. 1989; Felber et al. 1989; Hammarskjöld et al. 1989; Malim et al. 1989b; Hope et al. 1990a; Malim and Cullen 1993). Rev binds directly to a cis-acting RNA target (Daly et al. 1989; Zapp and Green 1989), the Rev response element (or RRE) (Rosen et al. 1988; Hadzopoulou-Cladaras et al. 1989; Malim et al. 1989b), that is present in all 9- and 4-kb mRNAs and, by inducing their transport to the cytoplasm, activates their functional expression and, hence, their translation into the structural proteins of the virus (Feinberg et al. 1986; Sodroski et al. 1986; Knight et al. 1987). In the absence of Rev, these introncontaining transcripts are retained by the nucleus and either spliced to completion or subjected to degradation.

The Rev protein itself has been shown to contain two distinct functional domains, both of which are essential for trans-activation (Fig. 1). The larger of these is located toward the amino terminus and is centered around a re-

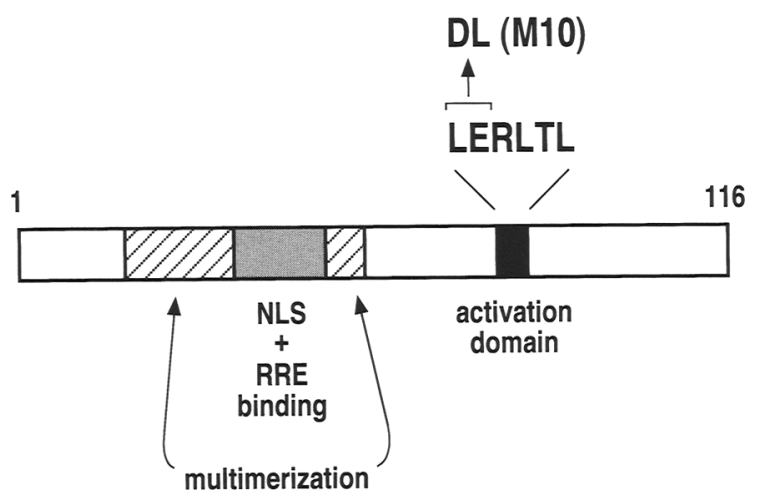

Figure 1. Domain organization of the HIV-1 Rev trans-activator. This hypothetical map of the 116-amino-acid Rev protein combines data derived from in vivo and in vitro experiments. The amino-terminal domain contains both an arginine-rich region (shaded box) that functions as the NLS and mediates RRE binding as well as flanking sequences required for multimerization (hatched boxes). The activation domain (solid box) has a defined core of 6 amino acids (Leu-Asp-Arg-Leu-Thr-Leu) and is located toward the carboxyl terminus. The amino acids that are altered in the dominant-negative mutant M10 are indicated (Leu-Asp $\rightarrow$ Glu-Leu). Nonessential sequences are shown as open boxes. gion rich in arginine residues (Malim et al. 1989a; Hope et al. 1990a,b; Olsen et al. 1990). In addition to conferring nuclear, and primarily nucleolar, localization on Rev (Malim et al. 1989a; Perkins et al. 1989), this domain also mediates the direct binding of Rev to the RRE and participates in the assembly of Rev into multimers (Olsen et al. 1990; Böhnlein et al. 1991; Malim and Cullen 1991; Zapp et al. 1991). The second essential domain contains three closely spaced leucine residues and is positioned toward the carboxyl terminus /Venkatesh and Chinnadurai 1990; Malim et al. 1991). The mutation of any of these leucines generates nonfunctional proteins (Malim et al. 1989a; Hope et al. 1990b; Mermer et al. 1990; Olsen et al. 1990; Venkatesh and Chinnadurai 1990) whose predominant accumulation in the nucleoli and ability to bind to the RRE are both indistinguishable from wild-type Rev (Malim et al. 1989a; Olsen et al. 1990; Malim and Cullen 1991; Zapp et al. 1991; Tiley et al. 1992; Daly et al. 1993). It has therefore been proposed that the defect in Rev mutants with this phenotype lies in their inability to interact with the nuclear factors, presumably proteins, required for the transport of unspliced HIV-1 mRNA to the cytoplasm (Malim et al. 1991). By analogy with a variety of proteins involved in transcription or splicing, this leucine-rich region has been operationally defined either as an activation domain or as an effector domain (Malim et al. 1989a; Zapp et al. 1991).

Given the potential importance of shuttling proteins to the nucleocytoplasmic transport of macromolecules and the clear influence of Rev on the subcellular distribution of HIV-1 mRNA, we wished to determine whether the Rev protein itself has the capacity to shuttle between the nucleus and the cytoplasm. In this paper we demonstrate that Rev, rather than being confined to the nucleus, is constantly shuttling in and out of the nucleus. The likely relevance of Rev's nuclear export to its function is underscored by the finding that nonfunctional Rev mutants carrying defective activation domains are unable to enter the cytoplasm and are therefore confined to the nucleus. This latter observation is of particular significance as it defines, for the first time, a protein domain important for nuclear export.

\section{Results}

In the experiments described here, we have utilized assays based on indirect immunofluorescence to assess whether the Rev trans-activator of HIV-1 is, at any time, present in the cytoplasms of somatic cells. As noted previously by several laboratories, Rev localizes to the nucleus, and predominantly the nucleoli, of HeLa cells transiently transfected with a wild-type Rev expression vector, in this case pcREV (Fig. 2a,b; Cullen et al. 1988; Felber et al. 1989). Because Rev's function is to induce the transport of intron-containing HIV-1 transcripts to the cytoplasm, we then analyzed cells in which Rev and an unspliced Rev-responsive mRNA were both present. Cells were therefore cotransfected with pcREV and a second vector, termed pgTAT, whose unspliced tat tran- 
Figure 2. Subcellular localization of wildtype and M10 Rev proteins in transiently transfected HeLa cells. Immunofluorescence and corresponding phase-contrast analyses are presented for each culture. Thirty-five-millimeter subconfluent monolayers of HeLa cells were transfected with pcREV or pM10, either alone or in combination with the RRE expression vector pgTAT, as indicated. At $\sim 40 \mathrm{hr}$, and after replating onto Lab-Tek chamber slides, the cells were incubated either with $50 \mu \mathrm{g} / \mathrm{ml}$ of cycloheximide for $3.5 \mathrm{hr}(a-d, \mathrm{i}, j)$ or with cycloheximide for $30 \mathrm{~min}$ followed by 5 $\mu \mathrm{g} / \mathrm{ml}$ of actinomycin D (Act D) plus cycloheximide for an additional $3 \mathrm{hr}\{e-h, k, 1\}$. The fixed and permeabilized cells were hybridized initially with an anti-Rev monoclonal antibody and then with a goat antimouse antibody conjugated to Texas red. Samples were visualized at a magnification of $400 \times$. script is confined to the nucleus unless Rev is present (Malim et al. 1989b). Despite the added presence of unspliced RRE-containing mRNA in these cells, no perturbation of the nuclear and nucleolar pattern of Rev staining could be discerned (Fig. $2 \mathrm{c}$, d). One potential explanation for the lack of detection of Rev in the cytoplasms of these cultures was that the interaction of the RRE with Rev could have resulted in masking of the epitope recognized by this particular monoclonal antibody. This possibility was ruled out after further analyses employing a variety of antibodies specific for both amino and carboxy terminal regions of Rev yielded identical results (data not shown).

Although Rev could only be detected in the nuclei and nucleoli of our transfected cells, we note that a number of the proteins now known to shuttle were initially described as being nuclear; for example, the hnRNP Al protein is nucleoplasmic in proliferating somatic cells (Piñol-Roma and Dreyfuss 1991), whereas nucleolin and B23/No38 appear primarily nucleolar (Borer et al. 1989). Recently, it was demonstrated that continuing RNA polymerase II-dependent transcription is essential for the localization of the hnRNP Al protein to the nucleus $(\mathrm{Pi}$ nol-Roma and Dreyfuss 1992). Thus, inhibiting transcription resulted in the accumulation of $\mathrm{Al}$ in the cytoplasm, presumably as a consequence of the import leg, but not the export leg, of the shuttling cycle being sensitive to the activity of RNA polymerase II. The importance of transcription to the nuclear localization of Rev was therefore evaluated. Approximately $40 \mathrm{hr}$ after transfection with pcREV, either alone or with pgTAT, cells were incubated for $3 \mathrm{hr}$ in medium supplemented with $5 \mu \mathrm{g} / \mathrm{ml}$ of the transcription inhibitor actinomycin D (Perry and Kelley 1970). Irrespective of the presence of RRE-containing transcripts in these cells, the repression of transcription resulted in a significant fraction of Rev accumulating in the cytoplasm (Fig. 2e-h). Importantly, the translation inhibitor cycloheximide was added to these cultures $30 \mathrm{~min}$ prior to the inhibition of transcription and was maintained in the medium thereafter. This ensured that all of the Rev detected in the cytoplasms of these cells represented protein that had been exported from the nucleus rather than newly synthesized protein that had never entered the nucleus. Rev's accumulation in the cytoplasm can, however, be attributed directly to the addition of actinomycin $\mathrm{D}$ and not to the arrest of protein synthesis, because treatment with cycloheximide alone yielded the same nuclear and nucleolar pattern of Rev expression as seen in untreated cells (Fig. 2a-d and data not shown).

Having shown that the wild-type Rev protein can migrate from the nucleus to the cytoplasm, we then wanted to determine how a genetically defined nonfunctional mutant of Rev, known as M10 (Malim et al. 1989a), would respond to the inhibition of transcription. This inactive Rev protein carries a mutation in its leucinerich activation domain (Fig. 1) that renders it incapable of activating the export of intron-containing HIV-1 transcripts to the cytoplasm. As discussed earlier, mutants of this type exhibit RRE binding and nucleolar localization characteristics that are indistinguishable from those of the wild-type protein (Fig. 2i,j; Malim et al. 1989a; Olsen et al. 1990; Malim and Cullen 1991; Zapp et al. 1991; Daly et al. 1993). Importantly, and in striking contrast to Rev, the M10 protein failed to accumulate in the cytoplasms of transfected HeLa cells following treatment with $5 \mu \mathrm{g} / \mathrm{ml}$ of actinomycin D (Fig. 2k,1). Because M10 is a nonfunctional mutant unable to induce RNA export, it was not surprising that it was also confined to the nuclei of cells that had been cotransfected with pgTAT and treated with actinomycin D (data not shown). Although these findings indicate that the inactivation of Rev's activation domain prevents Rev from exiting the nucleus, it was important to establish that this behavior is not unique to M10. A series of functional (M20, M34, M35) and other nonfunctional (M27, M28, M29, M32) Rev proteins carrying a variety of missense mutations in their respective activation domains were therefore scored for their ability to accumulate in the cytoplasms of cells treated with $5 \mu \mathrm{g} / \mathrm{ml}$ of actinomycin D (Table 1 ). A perfect correlation between the in vivo activity of these mutants and their ability to enter the cytoplasm 
Table 1. Correlation between biological activity and nuclear export for activation domain mutants of Rev

\begin{tabular}{llcc}
\hline Designation & Mutation & $\begin{array}{l}\text { Biological } \\
\text { activity }\end{array}$ & $\begin{array}{l}\text { Nuclear } \\
\text { export }\end{array}$ \\
\hline Wild type & ${ }^{78} \mathrm{LE}^{79} \rightarrow \mathrm{DL}$ & + & + \\
M10 & ${ }^{79} \mathrm{ER}^{80} \rightarrow \mathrm{DL}$ & - & - \\
M20 & ${ }^{78} \mathrm{~L} \rightarrow \mathrm{A}$ & + & + \\
M27 & ${ }^{81} \mathrm{~L} \rightarrow \mathrm{A}$ & - & - \\
M28 & ${ }^{83} \mathrm{~L} \rightarrow \mathrm{A}$ & - & - \\
M29 & ${ }^{78} \mathrm{LERLTL}^{83} \rightarrow$ AERATA & - & - \\
M32 & ${ }^{84} \mathrm{D} \rightarrow \mathrm{V}$ & + & - \\
M34 & ${ }^{79} \mathrm{E} \rightarrow \mathrm{Q}$ & + & + \\
M35 & & +
\end{tabular}

The in vivo phenotypes of these mutant Rev proteins have been described previously (Malim et al. 1991). Their respective capacities for nuclear export were determined by immunofluorescence following actinomycin D $(5 \mu \mathrm{g} / \mathrm{ml})$ treatment of transfected HeLa cells, as described for Fig. 2.

was observed. These results demonstrate that an inability to exit the nucleus is a characteristic of all activation domain-defective Rev mutants and suggest, moreover, that Rev's ability to enter the cytoplasm and its function as a trans-activator of nucleocytoplasmic viral mRNA transport may be related.

Before proceeding with our next series of experiments, we wanted to increase the percentage of cells within a culture that expressed either the wild-type Rev protein or the M10 mutant. HeLa cell lines, termed $\mathrm{He} / \mathrm{Rev}$ and $\mathrm{He} / \mathrm{MlO}$, respectively, were therefore derived by stable transfection. Metabolic labeling of these two cell lines, as well as untransfected HeLa cells, followed by immunoprecipitation using a Rev-specific antiserum confirmed that Rev proteins of the expected relative molecular mass $(\sim 18 \mathrm{kD})$ were being expressed (Fig. 3, lanes $1,3,5)$. Because all the experiments that follow depend on protein synthesis being inhibited for the duration of the experiment, it was important for us to establish that cycloheximide was a potent repressor of translation in these cells. When the labeling was performed in the presence of cycloheximide, we were unable to detect the synthesis of either Rev protein (Fig. 3, lanes 4,6). We have also shown that the He/Rev line, but not the He/MlO line, rescued viral Gag protein synthesis following transient transfection with an HIV-1 proviral expression vector that lacked a functional rev gene. This confirmed that the Rev proteins being produced by these two cell lines had maintained their established phenotypes /data not shown).

Immunofluorescence analyses of transcriptionally active cultures of both HeLa cell lines showed Rev and M10 to be localized to the nuclei and nucleoli in a manner indistinguishable from each other and from that noted earlier in transiently transfected cells (cf. Fig. 4, a and c, with Fig. 2, a and i). In further agreement with our earlier findings, the addition of $5 \mu \mathrm{g} / \mathrm{ml}$ of actinomycin $\mathrm{D}$ for $3 \mathrm{hr}$, in the presence of cycloheximide, resulted in the wild-type Rev protein accumulating in the cyto-

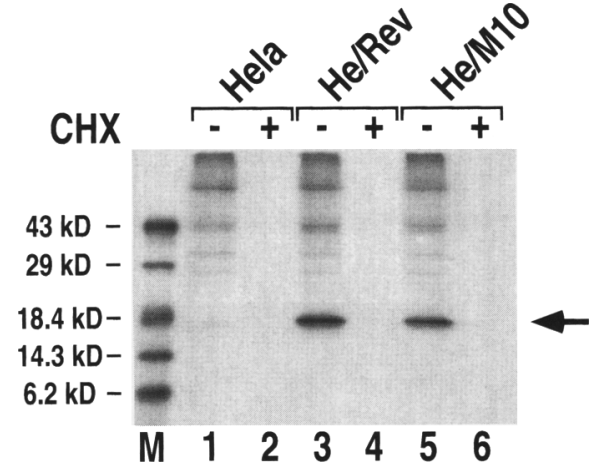

Figure 3. Expression of wild-type and M10 Rev proteins in stable HeLa cell lines. Thirty-five-millimeter cultures of untransfected HeLa (lanes 1,2), He/Rev (lanes 3,4), and $\mathrm{He} / \mathrm{MlO}$ $($ lanes 5,6$)$ cells were metabolically labeled with $\left[{ }^{35}\right.$ S $]$ cysteine in the presence or absence of $50 \mu \mathrm{g} / \mathrm{ml}$ of cycloheximide $(\mathrm{CHX}$ ) as indicated. Rev proteins were immunoprecipitated with a rabbit antipeptide serum, resolved on a $14 \%$ SDS-polyacrylamide gel, and visualized by autoradiography. Low-molecular-mass protein standards were loaded in lane $M$. The bands corresponding to the Rev proteins are indicated with the arrow.

plasm and in M10 being fully retained by the nucleus (Fig. 4b,d). Because this concentration of actinomycin D inhibits RNA polymerases I and II, we then treated cultures of both lines with either $0.04 \mu \mathrm{g} / \mathrm{ml}$ of actinomycin D or $100 \mu \mathrm{M}$ 5,6-dichloro-1- $\beta$-D-ribofuranosylbenzimidazole (DRB) to inhibit, respectively, RNA polymerase I- or RNA polymerase II-dependent transcription (Perry and Kelley 1970; Sehgal et al. 1976). Whereas the inhibition of polymerase I had minimal impact on the subcellular distribution of either Rev protein (data not shown), the repression of RNA polymerase II alone by DRB led to the relocalization of wild-type Rev, but not M10, to the cytoplasm (Fig. 5a; data not shown). Taken together, these findings demonstrate that the accumulation of Rev in the nuclei of cells during interphase is dependent on the activity of RNA polymerase II.

In many of the experimental systems used for studying

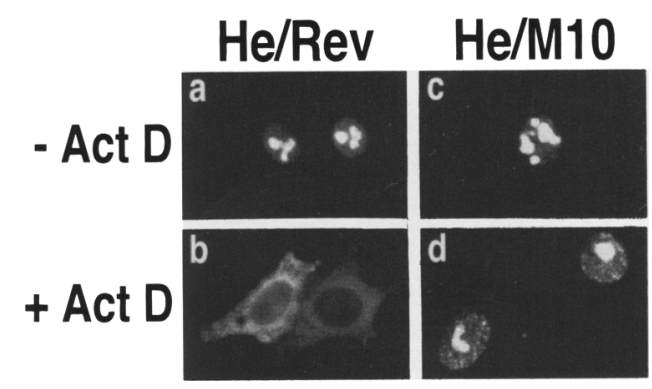

Figure 4. Wild-type Rev, but not M10, accumulates in the cytoplasms of cells treated with $5 \mu \mathrm{g} / \mathrm{ml}$ of actinomycin D. Monolayer cultures of $\mathrm{He} / \operatorname{Rev}(a, b)$ and $\mathrm{He} / \mathrm{MlO}(c, d)$ were incubated with $(b, d)$ or without $(a, c)$ actinomycin $\mathrm{D}$ in the presence of cycloheximide for $3 \mathrm{hr}$ as indicated and analyzed by immunofluorescence as in Fig. 1. 


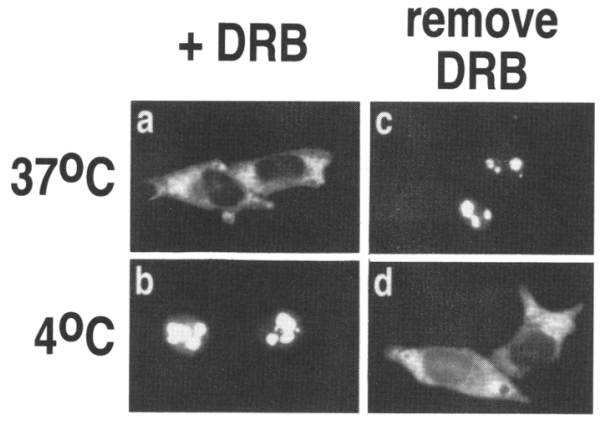

Figure 5. Temperature dependence and reversibility of Rev's accumulation in the cytoplasm. He/Rev cultures were maintained in cycloheximide and incubated at $37^{\circ} \mathrm{C}(a)$ or $4^{\circ} \mathrm{C}(b)$ with $100 \mu \mathrm{M} D R B$ for $3 \mathrm{hr}$. Cultures treated at $37^{\circ} \mathrm{C}$ were washed free of $\mathrm{DRB}$ and maintained at $37^{\circ} \mathrm{C}(\mathrm{c})$ or $4^{\circ} \mathrm{C}(d)$ for an additional $2 \mathrm{hr}$. Samples were analyzed by immunofluorescence as in Fig. 1.

nucleocytoplasmic trafficking, the transport of macromolecules in either direction across the nuclear membrane has been shown to be energy dependent (Dingwall et al. 1982; Richardson et al. 1988; Breeuwer and Goldfarb 1990; Mandell and Feldherr 1990; Dargemont and Kühn 1992; Piñol-Roma and Dreyfuss 1992). To determine the energy requirements for Rev's egress out of the nucleus, cultures of $\mathrm{He} / \mathrm{Rev}$ were treated with $\mathrm{DRB}$ at $37^{\circ} \mathrm{C}$ or $4^{\circ} \mathrm{C}$ (Fig. $5 \mathrm{a}, \mathrm{b}$ ). That Rev only accumulated in the cytoplasms of cells incubated at $37^{\circ} \mathrm{C}$ is indicative of Rev's export being mediated by a process that requires energy. By subsequently withdrawing the DRB from $\mathrm{He} /$ Rev cultures incubated at $37^{\circ} \mathrm{C}$ and then maintaining them in DRB-free medium at $37^{\circ} \mathrm{C}$ or $4^{\circ} \mathrm{C}$, it was further established that the migration of Rev to the cytoplasm is, by definition, fully reversible (Fig. 5c) and that its reimport back into the nucleus requires energy utilization (Fig. 5d). In summary, these observations not only indicate that the wild-type Rev protein shuttles but also that active processes are involved in both the export and import segments of the shuttling cycle.

Although the data presented to this point strongly suggest that Rev constitutively exits and then reenters the nucleus, we nevertheless wanted to confirm this by uti- lizing an assay system in which transcription was not inhibited. To this end, we adopted an approach, namely the formation of interspecies heterokaryons, that has been used successfully by a number of laboratories to confirm that certain nuclear proteins shuttle to and from the cytoplasm (Borer et al. 1989; Guiochon-Mantel et al. 1991; Piñol-Roma and Dreyfuss 1992; Madan and DeFranco 1993; Schmidt-Zachmann et al. 1993). The HeLa cell lines expressing Rev or M10 (the "donor" cells) were therefore fused to mouse cells not expressing Rev (the "acceptor" cells) with polyethylene glycol and maintained in cycloheximide-containing medium in the absence of transcription inhibitors for an additional 45 min. Following fixation, the heterokaryons were subjected to double-label immunofluorescence using antibodies specific for Rev and the nonshuttling human hnRNP Cl and C2 proteins (Piñol-Roma and Dreyfuss 1992). Because HeLa cells are of human origin, the donor nuclei within the heterokaryons were identified as those that contained the human $\mathrm{C}$ proteins, whereas the acceptor nuclei were identified as those that did not (Fig. 6, cf. a with $c$ and $d$ with f). In contrast to the predicted restriction of the $C$ proteins to the human cell-derived nuclei, the wild-type Rev protein was readily detected in both the acceptor and the donor nuclei of heterokaryons formed with the $\mathrm{He} / \mathrm{Rev}$ cells (Fig. $6 \mathrm{~b}$ ). Because protein synthesis had been inhibited for the duration of this experiment, the import of Rev into the mouse cell-derived nuclei must have been preceded both by its export out of the human nuclei and by its subsequent passage through the cytoplasm. Of particular significance, however, was the observation that the M10 mutant protein was, like the human $\mathrm{C}$ proteins, confined to the donor nuclei of $\mathrm{He} / \mathrm{M} 10$-derived heterokaryons (Fig. 6e). Because M10 is efficiently localized to the nuclei and nucleoli of expressing cells (see Fig. 4c), its inability to accumulate in the mouse cell-derived nuclei of these heterokaryons must have been a consequence of its inability to escape from the donor nuclei. From these results we have concluded that the wild-type Rev trans-activator does shuttle between the nuclear and cytoplasmic compartments of transcriptionally active cells but that mutant Rev proteins carrying nonfunctional activation domains do not.
Figure 6. Nucleocytoplasmic shuttling of HIV-1 Rev proteins in human-mouse interspecies heterokaryons. Mouse Ltk ${ }^{-}$cells were fused to $\mathrm{He} / \operatorname{Rev}(a-c)$ or $\mathrm{He} /$ M10 $|d-f|$ cells using polyethylene glycol and maintained at $37^{\circ} \mathrm{C}$ for an additional $45 \mathrm{~min}$ in cyclohexim ide-containing medium. Double-label immunofluorescence was then performed on fixed and permeabilized samples using monoclonal antibodies specific for the human hnRNP C proteins $(a, d)$ and $\operatorname{Rev}(b, e)$. The positions of the human (hul and mouse (mo) nuclei are indicated with arrows. The corresponding phase-contrast images of the heterokaryons are also shown $(c, f)$.

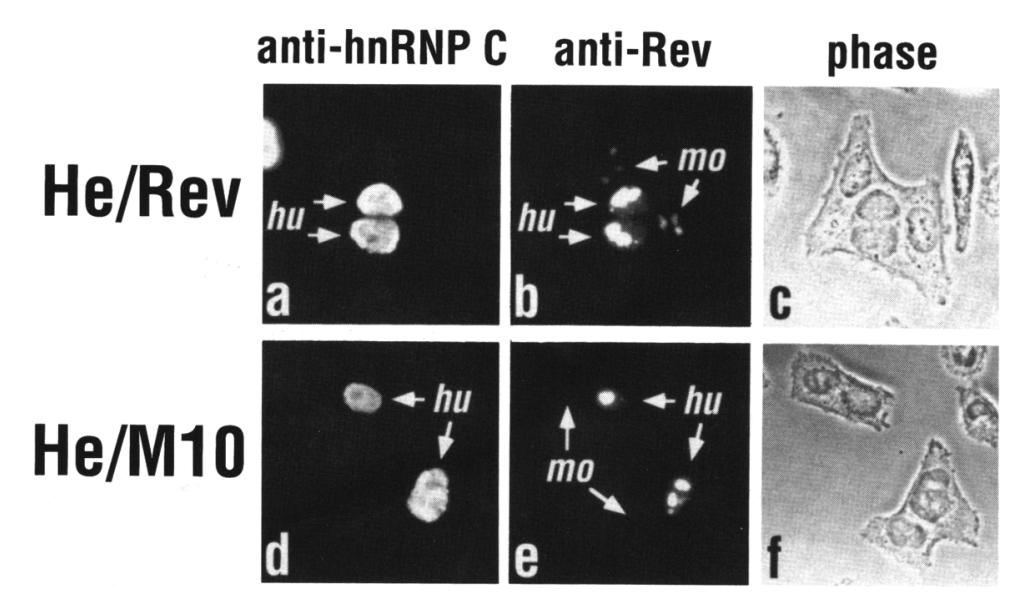




\section{Discussion}

In this paper we have used two different assay systems to show that the HIV-1 Rev trans-activator is not, as thought previously, confined solely to the nucleus. Although the indirect immunofluorescent analysis of proliferating cells shows that all detectable Rev localizes to the nucleus at any given time (Figs. 2 and 4; Cullen et al. 1988; Felber et al. 1989), the data presented here reveal that much of this protein is, to be accurate, in a state of constant flux between the nucleus and the cytoplasm. However, because the relative molecular mass of Rev is $\sim 18 \mathrm{kD}$ and the diffusion limit of nuclear pores is estimated to be $\sim 60 \mathrm{kD}$ (for review, see Nigg et al. 1991; Davis 1992; Forbes 1992), it was particularly important for us to establish that Rev's export to the cytoplasm is a specific event and not merely the manifestation of passive diffusion away from an area of high protein concentration in the nucleus.

Accordingly, we have provided two lines of evidence which, when taken together, are consistent with Rev's nucleocytoplasmic transport occurring by a process that requires a specific protein sequence and is dependent on energy utilization. First, in both transcription inhibition and heterokaryon experiments we demonstrate that Rev mutants with nonfunctional activation domains, which like $\mathrm{Rev}$ have relative molecular masses of $\sim 18 \mathrm{kD}$, are unable to migrate out of the nucleus (Figs. 2, 4 and 6; Table 1). These observations establish the specificity of Rev's export to the cytoplasm and identify the leucinerich activation domain of Rev as being essential for this process. Second, we show that the rapid accumulation of Rev in the cytoplasms of cells treated with inhibitors of transcription is suppressed when the cells are incubated at $4^{\circ} \mathrm{C}$ instead of $37^{\circ} \mathrm{C}$ (Fig. 5), a result consistent with export being an active process. Had the movement of Rev out of the nucleus been driven merely by diffusion down a concentration gradient, then reducing the temperature would not have been expected to have such a profound inhibitory effect. The finding that the Rev protein of HIV-1 constitutively shuttles between the nucleus and the cytoplasm has implications both for the mechanism of Rev-mediated trans-activation and for understanding how proteins are exported out of the nucleus.

\section{Mechanism of Rev trans-activation}

The HIV-1 Rev trans-activator is absolutely required for expression of unspliced $\sim 9-\mathrm{kb}$ and singly spliced $\sim 4-\mathrm{kb}$ HIV-1 transcripts in the cytoplasm. Because these transcripts represent both the genomic RNA found in viral particles (9-kb transcripts only) as well as the templates for translation of the viral structural proteins, for example, Gag and Env, their cytoplasmic expression is essential for viral replication (Feinberg et al. 1986; Sodroski et al. 1986). Although it is generally accepted that Rev acts by inducing the translocation of intron-containing viral transcripts to the cytoplasm, the precise mechanism of trans-activation still remains to be elucidated. In partic- ular, experiments in support of Rev operating either as an inhibitor of spliceosome assembly (Kjems et al. 1991; Kjems and Sharp 1993) and, hence, of viral mRNA splicing, or as a direct activator of mRNA export have been described (Emerman et al. 1989; Felber et al. 1989; Hammarskjöld et al. 1989; Malim et al. 1989b). Importantly, a recent study that used HIV-1-infected human T cells as the experimental system demonstrated that the Rev-dependent transport of 9 - and $4-\mathrm{kb}$ viral mRNAs to the cytoplasm occurs in the absence of any discernible effect on the level of expression of the fully spliced $\sim 2-\mathrm{kb}$ transcripts (Malim and Cullen 1993). Because a splicing-inhibition model would predict that expression of the $2-\mathrm{kb}$ mRNAs would be reduced by Rev, this finding strongly supports the alternative viewpoint that Rev's primary function is to activate the nucleocytoplasmic transport of intron-containing viral mRNAs.

The demonstration that mutations in Rev's activation domain (e.g., M10) that abolish trans-activation also prevent Rev from entering the cytoplasm is therefore suggestive of the following model for the Rev-mediated induction of viral mRNA transport. After transcription, the full-length $9-\mathrm{kb}$ transcript is spliced inefficiently to yield a heterogeneous population of viral transcripts in the nucleus that includes the 9-kb mRNA as well as 4and $2-\mathrm{kb}$ mRNAs. When Rev is present in sufficient abundance, it binds to the 9- and 4-kb mRNAs, via the RRE, to form ribonucleoprotein complexes that contain both Rev and viral RNA. Because Rev's leucine-rich activation domain is thought to mediate Rev-host cell protein interactions (Malim et al. 1991), we hypothesize that such an interaction then takes place and the RevmRNA complexes are programmed for export to the cytoplasm. As illustrated by mutants such as M10, failure to participate in a protein-protein interaction of this type results in Rev as well as the unspliced viral transcripts being confined to the nucleus. Once in the cytoplasm, and perhaps after subserving a function there, we imagine that Rev completes the shuttling cycle by disengaging from the RNA and returning to the nucleus by a process that requires both its arginine-rich NLS (Malim et al. 1989a; Perkins et al. 1989) and RNA polymerase II-dependent transcription. Interestingly, in vitro-binding experiments have shown that Rev can interact with the nucleolar shuttling protein B23/No38 (Fankhauser et al. 1991). Whether the shuttling of this protein has any influence on the activity and shuttling of Rev remains an open and intriguing question.

It has been predicted previously that proteins shuttling across the nuclear envelope are likely to be involved in the transport of proteins and RNAs between the nucleus and the cytoplasm (for review, see Goldfarb 1991; Laskey and Dingwall 1993). The discovery that Rev, a known activator of RNA transport, is also a shuttle protein appears to bear out this prediction. Interestingly, human T-cell leukemia virus type I (HTLV-I), a human retrovirus that is very distinct from HIV-1, also encodes a nuclear trans-activator that is essential for the expression of its unspliced mRNAs in the cytoplasm (Hidaka et al. 1988; Siomi et al. 1988; Hanly et al. 1989|. Although this 
protein, termed Rex, shares little amino acid similarity with Rev, it too binds to viral mRNA (Ballaun et al. 1991; Bogerd et al. 1991) and is able to enter the cytoplasm (data not shown). The hypothesis that these two viral RNA-binding proteins each play a direct role in the transport of their RNA substrates to the cytoplasm is fully consistent with models developed in certain nonviral systems. In particular, evidence has been presented to suggest that the shuttling of the mRNA-binding hnRNP A1 protein (Piñol-Roma and Dreyfuss 1992) as well as the nuclear export of the 5S rRNA-binding L5 and TFIIIA proteins (Guddat et al. 1990) is, in each case, intimately linked to the transport of the respective RNA ligand to the cytoplasm.

\section{Implications for nuclear export}

The notion that shuttling, and therefore nuclear export, is a specific process limited to a relatively small number of proteins has been challenged by the results of Schmidt-Zachmann and co-workers (1993). In a recent paper these investigators demonstrated that (1) no specific peptide sequence was required for the shuttling of the nucleolin, (2) the movement of a microinjected NLSpyruvate kinase fusion protein from the nucleus to the cytoplasm was suppressed by the addition of an RNAbinding domain (RNP) from nucleolin, and $\{3 \mid$ the nonshuttling chicken lamin $B_{2}$ was converted into a shuttle protein by the deletion of 27 amino acids from its amino terminus. Together, these findings have been taken as evidence that nuclear export, rather than being determined by specific peptide sequences is, instead, modulated by the extent of nuclear retention. Thus, shuttling may be a general property of any nuclear protein that is incompletely sequestered by the nucleus.

This hypothesis contrasts with the conclusions of an earlier study in which the fates of bovine serum albumin (BSA), the B3 and B4 heat shock-related proteins of $\mathrm{Xe}$ nopus, and the rat heat shock cognate (hsc) protein hsc 70 (all of which have relative molecular masses of $\sim 70-\mathrm{kD}$ ) were examined following their microinjection into the nucleus (Mandell and Feldherr 1990). Whereas BSA remained confined to the nucleus, $\sim 50 \%$ of the injected B3/B4 or hsc 70 entered the cytoplasm within $2 \mathrm{hr}$ of microinjection. Because a protein such as BSA is unlikely to contain a nuclear retention sequence, the rapid egress of B3/B4 and hsc70 from the injected nuclei indicates that these proteins contain specific nuclear export sequences but that BSA does not. Importantly, the failure of BSA to migrate to the cytoplasm following microinjection into the nucleus is not a unique property of BSA, for example, immunoglobulins and the trypsin-resistant pentameric core of nucleoplasmin are also excluded from the cytoplasm following direct introduction into the nucleus (Dingwall et al. 1982, 1988; Borer et al. 1989; Guiochon-Mantel et al. 1991).

The demonstration that inactivating mutations in Rev's leucine-rich activation domain (Fig. 1) inhibit nuclear export without disrupting RNA binding or nuclear localization supports the latter of the two viewpoints expounded above, namely, that export can be modulated by specific sequences. The specificity with which inactivation of this domain prevents export was further underscored by our finding that an inactive mutant of Rev that possesses a wild-type activation domain was still able to exit the nucleus (data not shown). This particular mutant, M7, carries a mutation in the amino-terminal essential domain (Fig. 1) that inhibits Rev's assembly into multimers but does not significantly affect its accumulation in the nucleus or its binding to RNA (Malim et al. 1989a, Malim and Cullen 1991). Thus, a loss of export capability is not a general consequence of Rev inactivation; rather, it is a characteristic that is limited to $\mathrm{mu}$ tants with nonfunctional activation domains.

Although we consider it most likely that Rev's activation domain is involved in the export process itself, it is also conceivable that its function is to liberate Rev from a confining interaction in the nucleus that would then allow export to take place. However, we regard this possibility as unlikely for two reasons. First, it seems improbable that several distinct perturbations of Rev's activation domain would prevent Rev from entering the cytoplasm (Table 1) by, in each case, fortuitously creating a nuclear retention sequence. Second, both wild-type Rev and the M10 mutant appeared to redistribute freely throughout the nucleoplasm following the inhibition of transcription (Fig. le,k), a finding that appears to be inconsistent with the idea that mutants such as M10 are irreversibly tethered to particular regions of the nucleus. The question therefore becomes, How can the identification of a domain in Rev that is critical for its export to the cytoplasm be reconciled with the aforementioned observations regarding the nuclear transport of nucleolin?

The hypothesis that we would like to propose is that two mechanisms can account for the nuclear export of proteins. Specifically, transport to the cytoplasm can be determined either directly by the presence of an export signal, as we have suggested for Rev, or indirectly by the strength of retaining interactions in the nucleus, as is the case with nucleolin. Evidence that supports the view that there are two distinct modes of export can be derived from a comparison of the shuttling kinetics of these two proteins. In experiments that utilized interspecies heterokaryons, Rev accumulated in the acceptor nuclei within 45 min of cell fusion (Fig. $6 \mathrm{~b}$ ); conversely, it was $24 \mathrm{hr}$ before the relocalization of wild-type nucleolin could be detected (Schmidt-Zachmann et al. 1993). In summary, these findings raise the possibility that protein export that is governed by nuclear retention is relatively slow, whereas export that is signal mediated is relatively rapid.

Interestingly, analyses of the kinetics of mRNA transport have demonstrated that this too is a rapid process. For example, the bulk of nuclear polyadenylated mRNA escapes the nucleus within $20 \mathrm{~min}$ of inhibiting RNA polymerase II-dependent transcription (Penman et al. 1970), and transferrin receptor mRNA that is injected into the nucleus of a Xenopus oocyte enters the cytoplasm with a half-life of $\sim 2$ min (Dargemont and Kühn 
1992). Given that Rev is required for the nuclear export of HIV-1 mRNA, it is perhaps not surprising that it shuttles to and from the cytoplasm with kinetics of the more rapid variety.

\section{Materials and methods}

\section{Expression vectors}

pcREV constitutively expresses the wild-type HIV-1 Rev protein (Malim et al. 1988). Missense derivatives of this vector that carry mutations in Rev's leucine-rich activation domain encode proteins that are either nonfunctional (M10, M27, M28, M29, M32) or have retained wild-type activity (M20, M34, M35) (Malim et al. 1989a, 1991) (see Fig. 1; Table 1).pgTAT expresses an intron-containing tat transcript whose expression in the cytoplasm is dependent on Rev coexpression (Malim et al. 1988). For the construction of stable cell lines (see below), the pcREV and pM10 vectors were modified to further express the mouse dihydrofolate reductase gene, dhfr. This was accomplished by inserting a 1.8 -kb PvuII-BamHI dhfr-gene-containing restriction fragment, derived from pSV2-dhfr (Subramani et al. 1981), into the unique StuI sites of pcREV and pM10.

\section{Cell culture, transfections, and cell line construction}

The human and mouse cell lines HeLa and Ltk ${ }^{-}$were maintained in Iscove's modified Dulbecco's medium supplemented with $10 \%$ fetal bovine serum and transfected (HeLa cells only) using calcium phosphate (Cullen 1987). To obtain HeLa cell lines that stably express the wild-type Rev protein or the M10 mutant, termed He/Rev and He/M10, $5 \mu \mathrm{g}$ of the appropriate $d h f r$-containing plasmid was linearized with $P v u I$ and cotransfected with $0.25 \mu \mathrm{g}$ of linearized pSV2-neo (Southern and Berg 1982) using calcium phosphate. Following $\sim 2$ weeks of selection in $0.8 \mathrm{mg} / \mathrm{ml}$ of G418 (GIBCO BRL, Gaithersburg, MD), the pools of resistant cells were replated in selective medium containing $10^{-7} \mathrm{M}$ amethopterin (Sigma Chemical Co., St. Louis, MO). As these cultures became resistant, the level of amethopterin in the medium was gradually increased until a final concentration of $10^{-6} \mathrm{M}$ was attained. At this point, clonal populations were derived by limiting dilution and those expressing higher levels of the Rev proteins, as judged by immunofluorescence (see below), were used for further analysis. During the course of the experiments, cultures were supplemented variously with $50 \mu \mathrm{g} / \mathrm{ml}$ of cycloheximide (Calbiochem Corp., La Jolla, CA) to inhibit protein synthesis and $0.04 \mu \mathrm{g} / \mathrm{ml}$ of actinomycin D (Boehringer Mannheim Corp., Indianapolis, IN), 100 $\mu \mathrm{M}$ DRB (Calbiochem), or $5 \mu \mathrm{g} / \mathrm{ml}$ of actinomycin D to inhibit transcription directed by RNA polymerase I, RNA polymerase II, or both, respectively (Perry and Kelley 1970; Sehgal et al. 1976).

\section{Indirect immunofluorescence and antibodies}

Cells plated onto Lab-Tek chamber slides (Nunc Inc., Naperville, IL) were used for the determination of subcellular localization. In experiments requiring the transient transfection of HeLa cells, analyses were performed $\sim 40 \mathrm{hr}$ after the addition of DNA to the monolayers. Cells were fixed using paraformaldehyde and permeabilized with Triton-X100 as described (Ruben et al. 1989|. For all experiments, except those involving heterokaryons (see below), Rev was detected with an anti-Rev monoclonal antibody (Repligen Corp., Cambridge, MA) at $1.25 \mu \mathrm{g} /$ $\mathrm{ml}$, followed by a goat antimouse antibody conjugated to Texas red (FisherBiotech, Pittsburgh, PA). Samples were then visual- ized by epifluorescence using a Nikon Microphot-FXA microscope at a magnification of $400 \times$.

\section{Immunoprecipitation}

Rev proteins from HeLa cells starved for $1 \mathrm{hr}$ and metabolically labeled for $2 \mathrm{hr}$ with $\left[{ }^{35} \mathrm{~S}\right.$ ) cysteine (Amersham Corp., Arlington, IL) were immunoprecipitated with a 1:150 dilution of a rabbit antipeptide serum, resolved on 14\% SDS-polyacrylamide gels, and visualized by autoradiography (Cullen et al. 1988; Malim et al. 1988|. When the labeling was performed in the presence of cycloheximide, the cycloheximide was also included in the culture medium for the last $30 \mathrm{~min}$ of the starvation step.

\section{Interspecies heterokaryons}

To form heterokaryons, mouse $\mathrm{Ltk}^{-}$cells were first grown to subconfluence on glass coverslips. Suspensions of $\mathrm{He} / \mathrm{Rev}$ or $\mathrm{He} / \mathrm{MlO}$ in complete medium were then added, and the cells allowed to settle for $3.5 \mathrm{hr}$. Then, the medium was exchanged for medium supplemented with $100 \mu \mathrm{g} / \mathrm{ml}$ of cycloheximide and the cells incubated for a further $30 \mathrm{~min}$; this was done to ensure that all of the Rev protein was, at the time of heterokaryon formation, localized to the nucleus. Cell fusion was performed by adding $50 \%$ polyethylene glycol 4000 (GIBCO $\mathrm{BRL}$ ) for $105 \mathrm{sec}$ at $37^{\circ} \mathrm{C}$; the cultures were then washed twice with prewarmed $\mathrm{PBS}$ and incubated for an additional $45 \mathrm{~min}$ at $37^{\circ} \mathrm{C}$ in complete medium containing cycloheximide. Fixed and permeabilized samples were subjected to double-label immunofluorescence using monoclonal antibodies specific for the human hnRNP C1 and C2 proteins (termed 4F4; see Piñol-Roma and Dreyfuss 1991) and Rev (Repligen); these primary antibodies were detected, respectively, with fluorescein isothiocyanate conjugated anti- $\gamma 1$ and Texas red-conjugated anti- $\gamma 2 \mathrm{~b}$ subclassspecific antimouse antibodies raised in goats (FisherBiotech).

\section{Acknowledgments}

We thank Serafín Piñol-Roma and Gideon Dreyfuss for the 4F4 antibody and for all their help and support, Kris Kelley for her expert assistance with the microscopy, Jim Alwine, Bob Doms, and Rebecca Oakey for their comments on the manuscript and Laurie Zimmerman for secretarial assistance. This work was supported by the Howard Hughes Medical Institute.

The publication costs of this article were defrayed in part by payment of page charges. This article must therefore be hereby marked "advertisement" in accordance with 18 USC section 1734 solely to indicate this fact.

\section{References}

Adam, S. and L. Gerace. 1991. Cytosolic proteins that specifically bind nuclear location signals are receptors for nuclear import. Cell 66: 837-847.

Ballaun, C., G.K. Farrington, M. Dobrovnik, J. Rusche, J. Hauber, and E. Böhnlein. 1991. Functional analysis of human T-cell leukemia virus type I Rex-response element: Direct RNA binding of Rex protein correlates with in vivo activity. J. Virol. 65: 4408-4413.

Bogerd, H.P., G.L. Huckaby, Y.F. Ahmed, S.M. Hanly, and W.C. Greene. 1991. The type I human T-cell leukemia virus (HTLV-I) Rex trans-activator binds directly to the HTLV-I Rex and the type 1 human immunodeficiency virus Rev RNA response elements. Proc. Natl. Acad. Sci. 88: 5704 5708.

Böhnlein, E., J. Berger, and J. Hauber. 1991. Functional mapping 
of the human immunodeficiency virus type 1 Rev RNA binding domain: New insights into the domain structure of Rev and Rex. I. Virol. 65: 7051-7055.

Borer, R.A., C.F. Lehner, H.M. Eppenberger, and E.A. Nigg. 1989. Major nucleolar proteins shuttle between nucleus and cytoplasm. Cell 56: 379-390.

Breeuwer, M. and D.S. Goldfarb. 1990. Facilitated nuclear transport of histone $\mathrm{Hl}$ and other small nucleophilic proteins. Cell 60: 999-1008.

Chang, D.D. and P.A. Sharp. 1989, Regulation by HIV Rev depends upon recognition of splice sites. Cell 59: 789-795.

Cullen, B.R. 1987. Use of eukaryotic expression technology in the functional analysis of cloned genes. Methods Enzymol. 152: 423-426.

-1991. Human immunodeficiency virus as a prototypic complex retrovinus. I. Virol. 65: 1053-1056.

Cullen, B.R., J. Hauber, K. Campbell, J.G. Sodroski, W.A. Haseltine, and C.A. Rosen. 1988. Subcellular localization of the human immunodeficiency virus trans-acting art gene product. J. Virol. 62: 2498-2501.

Daly, T.J., K.S. Cook, G.S. Gray, T.E. Maione, and J.R. Rusche. 1989. Specific binding of HIV-1 recombinant Rev protein to the Rev-responsive element in vitro. Nature 342: 816-819.

Daly, T.J., P. Rennert, J.K. Barry, M. Dundas, J.R. Rusche, R.C. Doten, M. Auer, and G.K. Farrington. 1993. Perturbation of the carboxy terminus of HIV-1 Rev affects multimerization on the Rev responsive element. Biochemistry 32: 89458954.

Dargemont, C. and L.C. Kühn. 1992. Export of mRNA from microinjected nuclei of Xenopus laevis oocytes. J. Cell Biol. 118: $1-9$.

Davis, L.I. 1992. Control of nucleocytoplasmic transport. Curr. Opin. Cell Biol. 4: 424-429.

Dingwall, C. and R.A. Laskey. 1992. The nuclear membrane. Science 258: 942-947.

- 1991. Nuclear targeting sequences-a consensus? Trends Biochem. Sci. 16: 478-481.

Dingwall, C., S.V. Sharnick, and R.A. Laskey. 1982. A polypeptide domain that specifies migration of nucleoplasmin into the nucleus. Cell 30: 449-458.

Dingwall, C., J. Robbins, S.M. Dilworth, B. Roberts, and W.D. Richardson. 1988. The nucleoplasmin nuclear location sequence is larger and more complex than that of SV-40 large T antigen. J. Cell Biol. 107: 841-849.

Dworetzky, S.I. and C.M. Feldherr. 1988. Translocation of RNA-coated gold particles through the nuclear pores of oocytes. J. Cell Biol. 106: 575-584.

Emerman, M., R. Vazeux, and K. Peden. 1989. The rev gene product of the human immunodeficiency virus affects envelope-specific RNA localization. Cell 57: 1155-1165.

Fankhauser, C., E. Izaurralde, Y. Adachi, P. Wingfield, and U.K. Laemmli. 1991. Specific complex of human immunodeficiency virus type $1 \mathrm{Rev}$ and nucleolar B23 proteins: Dissociation by the Rev response element. Mol. Cell. Biol. 11: $2567-2575$.

Feinberg, M.B., R.F. Jarrett, A. Aldovini, R.C. Gallo, and F. Wong-Staal. 1986. HTLV-III expression and production involve complex regulation at the levels of splicing and translation of viral RNA. Cell 46: 807-817.

Felber, B.K., C.M. Drysdale, and G.N. Pavlakis. 1990. Feedback regulation of human immunodeficiency virus type 1 expression by the Rev protein. J. Virol. 64: 3734-3741.

Felber, B.K., M. Hadzopoulou-Cladaras, C. Cladaras, T. Copeland, and G.N. Pavlakis. 1989. Rev protein of human immunodeficiency virus type 1 affects the stability and transport of the viral mRNA. Proc. Natl. Acad. Sci. 86: 1495-1499.
Feldherr, C.M., E. Kallenbach, and N. Schultz. 1984. Movement of a karyophilic protein through the nuclear pores of oocytes. J. Cell Biol. 99: 2216-2222.

Forbes, D.J. 1992. Structure and function of the nuclear pore complex. Annu. Rev. Cell Biol. 8: 495-527.

Garcia-Bustos, J., J. Heitman, and M.N. Hall. 1991. Nuclear protein localization. Biochim. Biophys. Acta 1071: 83-101.

Gerace, L. 1992. Molecular trafficking across the nuclear pore complex. Curr. Opin. Cell Biol. 4: 637-645.

Goldfarb, D.S. 1991. Shuttling proteins go both ways. Curr. Biol. 1: 212-214.

Goldfarb, D. and N. Michaud. 1991. Pathways for the nuclear transport of proteins and RNAs. Trends Cell Biol. 1: 20-24.

Guddat, U., A.H. Bakken, and T. Pieler. 1990. Protein-mediated nuclear export of RNA: 5S rRNA containing small RNPs in Xenopus oocytes. Cell 60: 619-628.

Guiochon-Mantel, A., P. Lescop, S. Christin-Maitre, H. Loosfelt, M. Perrot-Applanat, and W. Milgrom. 1991. Nucleocytoplasmic shuttling of the progesterone receptor. EMBO 10: 3851-3859.

Hadzopoulou-Cladaras, M., B.K. Felber, C. Cladaras, A. Athanassopoulos, A. Tse, and G.N. Pavlakis. 1989. The rev (trs/ art) protein of human immunodeficiency virus type 1 affects viral mRNA and protein expression via a cis-acting sequence in the env region. I. Virol. 63: 1265-1274.

Hammarskjöld, M.-L., J. Heimer, B. Hammarskjöld, I. Sangwan, L. Albert, and D. Rekosh. 1989. Regulation of human immunodeficiency virus env expression by the rev gene product. $J$. Virol. 63: 1959-1966.

Hanly, S.M., L.T. Rimsky, M.H. Malim, J.H. Kim, J. Hauber, M. Duc Dodon, S.-Y. Le, J.V. Maizel, B.R. Cullen, and W.C. Greene. 1989. Comparative analysis of the HTLV-I Rex and HIV-1 Rev trans-regulatory proteins and their RNA response elements. Genes \& Dev. 3: 1534-1544.

Hidaka, M., I. Inoue, M. Yoshida, and M. Seiki. 1988. Posttranscriptional regulator (rex) of HTLV-1 initiates expression of viral structural proteins but suppresses expression of regulatory proteins. $E M B O$ I. 7: 519-523.

Hinshaw, J.E., B.O. Carragher, and R.A. Milligan. 1992. Architecture and design of the nuclear pore complex. Cell 69: 1133-1141.

Hope, T.J., X. Huang, D. McDonald, and T.G. Parslow. 1990a. Steroid-receptor fusion of the human immunodeficiency virus type 1 Rev trans-activator: Mapping cryptic functions of the arginine-rich motif. Proc. Natl. Acad. Sci. 87: 77877791.

Hope, T.J., D. McDonald, X. Huang, J. Low, and T.G. Parslow. 1990b. Mutational analysis of the human immunodeficiency virus type 1 Rev trans-activator: Essential residues near the amino terminus. I. Virol. 64: 5360-5366.

Izaurralde, E. and I.W. Mattaj. 1992. Transport of RNA between nucleus and cytoplasm. Semin. Cell Biol. 3: 279-288.

Kambach, C. and I.W. Mattaj. 1992. Intracellular distribution of the U1A protein depends on active transport and nuclear binding to U1 snRNA. I. Cell Biol. 118: 11-21.

Kim, S., R. Byrn, J. Groopman, and D. Baltimore. 1989. Temporal aspects of DNA and RNA synthesis during human immunodeficiency virus infection: Evidence for differential gene expression. I. Virol. 63: 3708-3713.

Kjems, I. and P.A. Sharp. 1993. The basic domain of Rev from human immunodeficiency virus type 1 specifically blocks the entry of U4/U6. U5 small nuclear ribonucleoprotein in spliceosome assembly. J. Virol. 67: 4769-4776.

Kjems, J., A.D. Frankel, and P.A. Sharp. 1991. Specific regulation of mRNA splicing in vitro by a peptide from HIV-1 Rev. Cell 67: 169-178. 
Knight, D.M., F.A. Flomerfelt, and J. Ghrayeb. 1987. Expression of the art/trs protein of HIV and study of its role in viral envelope synthesis. Science 236: 837-840.

Laskey, R.A. and C. Dingwall. 1993. Nuclear shuttling: The default pathway for nuclear proteins? Cell 74: 585-586.

Madan, A.P. and D.B. DeFranco. 1993. Bidirectional transport of glucocorticoid receptors across the nuclear envelope. Proc. Natl. Acad. Sci. 90: 3588-3592.

Malim, M.H. and B.R. Cullen. 1991. HIV-1 structural gene expression requires the binding of multiple Rev monomers to the viral RRE: Implications for HIV-1 latency. Cell 65: 241248.

1993. Rev and the fate of pre-mRNA in the nucleus: Implications for the regulation of RNA processing in eukaryotes. Mol. Cell. Biol. 13: 6180-6189.

Malim, M.H., J. Hauber, R. Fenrick, and B.R. Cullen. 1988. Immunodeficiency virus rev trans-activator modulates the expression of the viral regulatory genes. Nature 335: 181-183.

Malim, M.H., S. Böhnlein, J. Hauber, and B.R. Cullen. 1989a. Functional dissection of the HIV-l Rev trans-activator-derivation of a trans-dominant repressor of Rev function. Cell 58: 205-214.

Malim, M.H., J. Hauber, S.-Y. Le, J.V. Maizel, and B.R. Cullen. 1989b. The HIV-1 rev trans-activator acts through a structured target sequence to activate nuclear export of unspliced viral mRNA. Nature 338: 254-257.

Malim, M.H., D.F. McCarn, L.S. Tiley, and B.R. Cullen. 1991. Mutational definition of the human immunodeficiency virus type 1 Rev activation domain. J. Virol. 65: 4248-4254.

Mandell, R.B. and C.M. Feldherr. 1990. Identification of two HSP70-related Xenopus oocyte proteins that are capable of recycling across the nuclear envelope. I. Cell Biol. 111: 1775-1783.

Meier, U.T. and G. Blobel. 1992. Nopp 140 shuttles on tracks between nucleolus and cytoplasm. Cell 70: 127-138.

Mermer, B., B.K. Felber, M. Campbell, and G.N. Pavlakis. 1990. Identification of trans-dominant HIV-1 Rev protein mutants by direct transfer of bacterially produced proteins into human cells. Nucleic Acids Res. 18: 2037-2044.

Muesing, M.A., D.H. Smith, C.D. Cabradilla, C.V. Benton, L.A. Lasky, and D.J. Capon. 1985. Nucleic acid structure and expression of the human AIDS/lymphadenopathy retrovirus. Nature 313: 450-458.

Nigg, E.A., P.A. Baeuerle, and R. Lührmann. 1991. Nuclear import-export: In search of signals and mechanisms. Cell 66: $15-22$.

Olsen, H.S., A.W. Cochrane, P.J. Dillon, C.M. Nalin, and C.A. Rosen. 1990. Interaction of the human immunodeficiency virus type $1 \mathrm{Rev}$ protein with a structured region in env mRNA is dependent on multimer formation mediated through a basic stretch of amino acids. Genes \& Dev. 4: 1357-1364.

Pavlakis, G.N. and B.K. Felber. 1990. Regulation of expression of human immunodeficiency virus. The New Biol. 2: 20-31.

Penman, S., M. Rosbash, and M. Penman. 1970. Messenger and heterogeneous nuclear RNA in HeLa cells: Differential inhibition by cordycepin. Proc. Natl. Acad. Sci. 67: 18781885.

Perkins, A., A.W. Cochrane, S.M. Ruben, and C.A. Rosen. 1989. Structural and functional characterization of the human immunodeficiency virus rev protein. J. Acquired Immune Defic. Syndr. 2: 256-263.

Perry, R.P. and D.E. Kelley. 1970. Inhibition of RNA synthesis by actinomycin D: Characteristic dose-response of different RNA species. I. Cell. Physiol. 76: 127-140.

Piñol-Roma, S. and G. Dreyfuss. 1991. Transcription-dependent and transcription-independent nuclear transport of hnRNP proteins. Science 253: 312-314.

-1992. Shuttling of pre-mRNA binding proteins between nucleus and cytoplasm. Nature 355: 730-732.

Richardson, W.D., A.D. Mills, S.M. Dilworth, R.A. Laskey, and C. Dingwall. 1988. Nuclear protein migration involves two steps: Rapid binding at the nuclear envelope followed by slower translocation through nuclear pores. Cell 52: 655664.

Robert-Guroff, M., M. Popovic, S. Gartner, P. Markham, R.C. Gallo, and M.S. Reitz. 1990. Structure and expression of tat-, rev-, and nef-specific transcripts of human immunodeficiency virus type 1 in infected lymphocytes and macrophages. $J$. Virol. 64: 3391-3398.

Rosen, C.A., E. Terwilliger, A. Dayton, J.G. Sodroski, and W.A. Haseltine. 1988. Intragenic cis-acting art gene-responsive sequences of the human immunodeficiency virus. Proc. Natl. Acad. Sci. 85: 2071-2075.

Ruben, S., A. Perkins, R. Purcell, K. Joung, R. Sia, R. Burghoff, W.A. Haseltine, and C.A. Rosen. 1989. Structural and functional characterization of human immunodeficiency virus tat protein. I. Virol. 63: 1-8.

Schmidt-Zachmann, M.S., C. Dargemont, L.C. Kühn, and E.A. Nigg. 1993. Nuclear export of proteins: The role of nuclear retention. Cell 74: 493-504.

Schwartz, S., B.K. Felber, D.M. Benko, E.-M. Fenyö, and G.N. Pavlakis. 1990. Cloning and functional analysis of multiply spliced mRNA species of human immunodeficiency virus type 1. J. Virol. 64: 2519-2529.

Sehgal, P.B., J.E. Darnell, and I. Tamm. 1976. The inhibition by DRB (5,6-dichloro-1- $\beta$-D-ribofuranosylbenzimidazole) of hnRNA and mRNA production in HeLa cells. Cell 9: 473480.

Siomi, H., H. Shida, S.H. Nam, T. Nosaka, M. Maki, and M. Hatanaka. 1988. Sequence requirements for nucleolar localization of human $\mathrm{T}$ cell leukemia virus type I pX protein, which regulates viral RNA processing. Cell 55: 197-209.

Sodroski, J., W.C. Goh, C.A. Rosen, A. Dayton, E. Terwilliger, and W.A. Haseltine. 1986. A second post-transcriptional trans-activator gene required for HTLV-III replication. $\mathrm{Na}$ ture 321: 412-417.

Southern, P.J. and P. Berg. 1982. Transformation of mammalian cells to antibiotic resistance with a bacterial gene under control of the SV40 early region promoter. J. Mol. Appl. Genet. 1: $327-341$.

Subramani, S., R. Mulligan, and P. Berg. 1981. Expression of the mouse dihydrofolate reductase complementary deoxyribonucleic acid in simian virus 40 vectors. Mol. Cell. Biol. 1: 854-864.

Tiley, L.S., S.J. Madore, M.H. Malim, and B.R. Cullen. 1992. The VP16 transcription activation domain is functional when targeted to a promoter-proximal RNA sequence. Genes \& Dev. 6: 2077-2087.

Venkatesh, L.K. and G. Chinnadurai. 1990. Mutants in a conserved region near the carboxy-terminus of HIV-l identify functionally important residues and exhibit a dominant negative phenotype. Virology 178: 327-330.

Warner, J.R. 1989. Synthesis of ribosomes in Saccharomyces cerevisiae. Microbiol. Rev. 53: 256-271.

Zapp, M.L. and M.R. Green. 1989. Sequence-specific RNA binding by the HIV-1 Rev protein. Nature 342: 714-716.

Zapp, M.L., T.J. Hope, T.G. Parslow, and M.R. Green. 1991. Oligomerization and RNA binding domains of the type 1 human immunodeficiency virus Rev protein: A dual function for an arginine-rich binding motif. Proc. Natl. Acad. Sci. 88: $7734-7738$. 


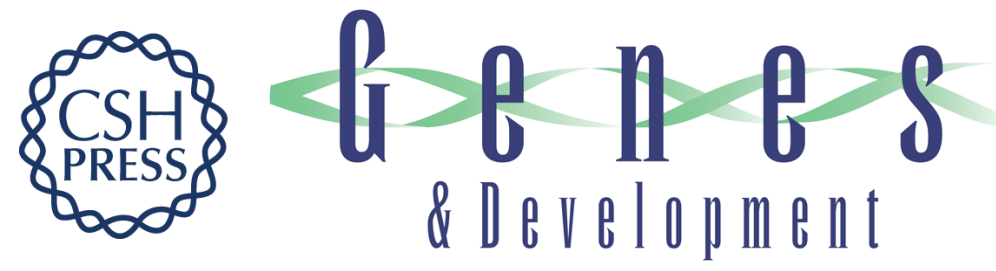

\section{The HIV-1 Rev trans-activator shuttles between the nucleus and the cytoplasm.}

B E Meyer and M H Malim

Genes Dev. 1994, 8:

Access the most recent version at doi:10.1101/gad.8.13.1538

References This article cites 81 articles, 37 of which can be accessed free at:

http://genesdev.cshlp.org/content/8/13/1538.full.html\#ref-list-1

License

Email Alerting

Service

Receive free email alerts when new articles cite this article - sign up in the box at the top right corner of the article or click here.

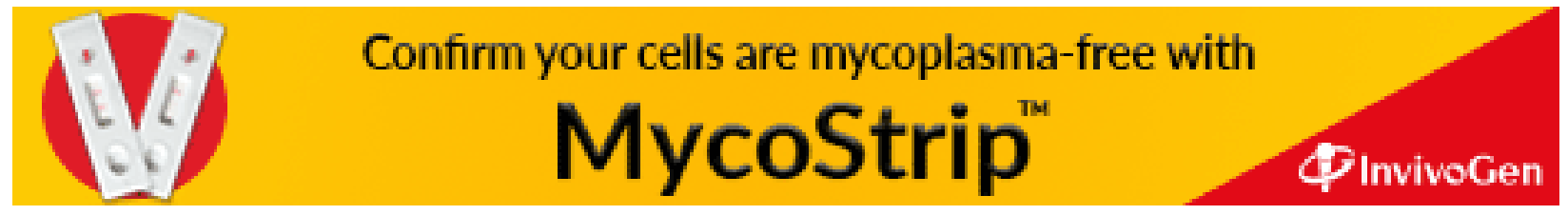

